Review began 11/09/2021 Review ended 11/16/2021 Published 11/17/2021

๑) Copyright 2021

Seixas et al. This is an open access article distributed under the terms of the Creative Commons Attribution License CC-BY 4.0. which permits unrestricted use, distribution, and reproduction in any medium, provided the original author and source are credited.

\section{Occurrence of Guillain-Barre Syndrome During the Initial Symptomatic Phase of COVID-19 Disease: Coincidence or Consequence?}

Rui Seixas ${ }^{1}$, David Campoamor ${ }^{1}$, João Lopes ${ }^{1}$, Teresa Bernardo ${ }^{1}$, Hipólito Nzwalo ${ }^{2,3}$, Dulce Pascoalinho 4

1. Department of Internal Medicine, Unidade Local de Saúde do Litoral Alentejano, Santiago do Cacém, PRT 2. Stroke Unit, Algarve University Hospital Center, Faro, PRT 3. Faculty of Medicine and Biomedical Sciences, University of Algarve, Faro, PRT 4. Department of Intensive Care, Unidade Local de Saúde do Litoral Alentejano, Santiago do Cacém, PRT

Corresponding author: Rui Seixas, ruipmseixas@gmail.com

\section{Abstract}

Viral infections are frequently present before the clinical manifestation of Guillain-Barre syndrome (GBS). Multiple studies on coronaviruses have shown that these viruses have neurotropic characteristics, and their molecular mimicry can induce inflammatory demyelinating neuropathy. Herein, we describe a case of a GBS in an 85-year-old patient infected with SARS-CoV-2, manifested with acute progressive symmetric ascending quadriparesis, urinary dysautonomia, and dysphagia, who responded well to treatment with intravenous human immunoglobulin.

Categories: Internal Medicine, Neurology, Infectious Disease

Keywords: viral mimicry, neurotropic virus, viral infections, covid-19, guillain barre syndrome

\section{Introduction}

Viral infections are frequently present before the clinical manifestation of Guillain-Barre syndrome (GBS) [1]. Antibodies against SARS-CoV-2 (severe acute respiratory syndrome coronavirus 2) can cross-react with peripheral myelin causing GBS since these viruses have neurotropic characteristics, and their molecular mimicry can induce inflammatory demyelinating neuropathy [2]. Thus, in patients with COVID-19, identification of unexplained neurological manifestations is crucial to early detection and management of GBS. The authors describe a case of an 85-year-old patient infected with SARS-CoV-2, with neurological symptoms of GBS and clinical improvement after treatment with intravenous human immunoglobulin.

\section{Case Presentation}

An 85-year-old female, previously independent, with a known medical history of congestive heart failure, atrial fibrillation, arterial hypertension, and no prior vaccination to SARS-CoV-2 or influenza, was admitted to the Emergency Department due to shortness of breath and cough for the past week. She also complained of progressive symmetric and ascending loss of muscle strength in the two days prior to hospitalization. The symptoms progressed from distal limbs to proximal limbs, with greater severity in both arms. She denied any other symptomatology, namely gastrointestinal symptoms. SARS-CoV-2 infection was confirmed by reverse transcription-polymerase chain reaction (RT-PCR) in nasopharyngeal swab sample. With the exception of mild hypoxemia on arterial gasometry, the remaining paraclinical investigation, including chest X-ray, was unremarkable. During the first day of hospitalization, the neurological symptoms worsened, and the patient developed urinary dysautonomia. A lumbar punction was performed, and cerebral spinal fluid (CSF) analysis revealed slight albumin-cytologic dissociation (Table 1). A comprehensive investigation excluded neurotropic viral infection, including SARS-CoV-2 and other infectious agents (Table 1). 


\section{Cureus}

\begin{tabular}{|c|c|}
\hline Cerebral spinal fluid - cytochemistry & Result \\
\hline Leukocytes & $1.0 \mathrm{~mm}^{3}$ (normal range: $0.0-5.0$ ) \\
\hline Predominant cells & Lymphocytes \\
\hline Glucose & $93.0 \mathrm{mg} / \mathrm{dL}$ (normal range: $40.0-70.0 \mathrm{mg} / \mathrm{dL}$ ) \\
\hline Chloride & $133.0 \mathrm{mEq} / \mathrm{L}$ (normal range: $118.0-132.0 \mathrm{mEq} / \mathrm{L}$ ) \\
\hline Microproteins & $47.0 \mathrm{mg} / \mathrm{dL}$ (normal range: $15.0-45.0 \mathrm{mg} / \mathrm{dL}$ ) \\
\hline Cerebral spinal fluid - neurotropic viruses & Result \\
\hline Herpes simplex (HSV-1 and HSV-2) & Negative \\
\hline Varicella zoster virus & Negative \\
\hline Epstein-Barr virus & Negative \\
\hline Cytomegalovirus & Negative \\
\hline Human herpesvirus (HHV6 and HHV7) & Negative \\
\hline Adenoviruses & Negative \\
\hline Poliovirus & Negative \\
\hline Enteroviruses & Negative \\
\hline SARS-CoV-2 & Negative \\
\hline Blood serum & Result \\
\hline Hepatitis C & Negative \\
\hline Hepatitis B & Negative \\
\hline HIV & Negative \\
\hline Treponema pallidum & Negative \\
\hline Nasopharyngeal swab & Result \\
\hline SARS-CoV-2 & Positive \\
\hline Influenza A and B & Negative \\
\hline Respiratory syncytial virus & Negative \\
\hline Imaging & Result \\
\hline Chest X-ray & Normal \\
\hline Brain tomography & Normal \\
\hline
\end{tabular}

TABLE 1: Comprehensive differential diagnosis investigation.

The presence of ascending quadriparesis, dysautonomia, and albumin-cytologic dissociation supported the diagnosis of GBS. Two days after admission, the patient was transferred to a level II intensive care unit and began treatment with intravenous human immunoglobulin with a daily dose of $0.4 \mathrm{gr}$ per $\mathrm{kg}$ for five consecutive days (total cumulative dosage of 2 grams per kg) without neurological improvement. The disease progressed with onset of bulbar symptoms, namely dysphagia (Figure 1). 


\section{Cureus}

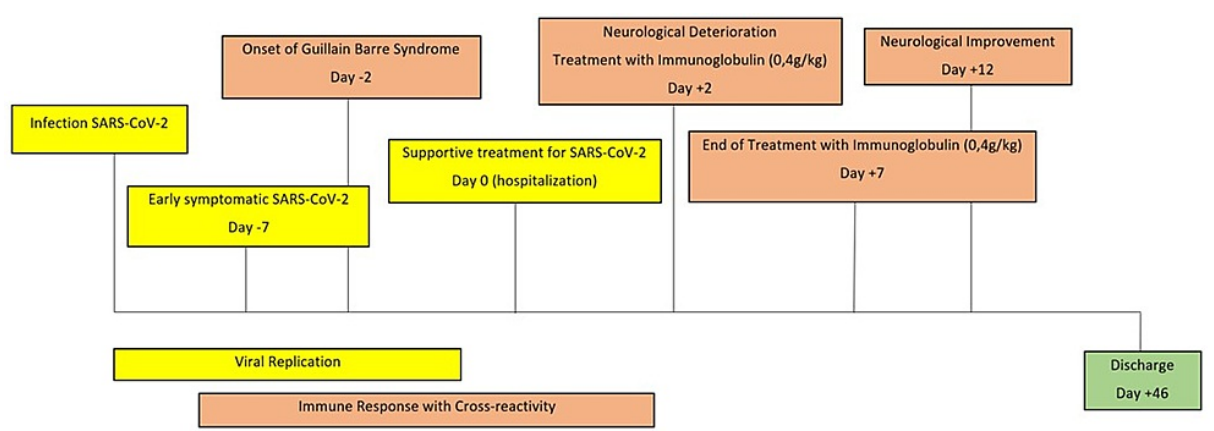

FIGURE 1: The chronological timeline of the patient's clinical course with essential findings and interventions.

Her hospitalization was prolonged due to aspiration nosocomial pneumonia requiring transient noninvasive ventilation. Finally, after 12 days post-admission, while still needing noninvasive ventilation, her neurological deficits slowly improved with physical rehabilitation, and she was discharged after 46 days of hospitalization, scoring 3 points on the modified Rankin scale. There was no need for corticotherapy.

\section{Discussion}

Infection by SARS-CoV-2 has been shown to lead to multiple neurological manifestations [3], with the most common being dizziness, headache, anosmia, and ageusia [4]. However, some isolated cases of GBS have also been reported worldwide [5]. Rather than a mere coincidence, the occurrence of GBS during early COVID-19 disease should be seen as an example of the SARS-CoV-2 virus' potential of inducing immunemediated neurological disease. The incubation period of SARS-CoV-2 infection can be as long as two weeks [6], and viral infections precede GBS's onset in days or weeks [7]. Hence, in this case, the hypothesis of SARS-CoV-2 antibodies cross-reacting with peripheral myelin causing GBS at the beginning of COVID-19 disease is very plausible. Moreover, multiple studies on coronaviruses have shown that these viruses have neurotropic characteristics [8], and molecular mimicry is a mechanism through which SARS-CoV-2 can trigger inflammatory demyelinating neuropathy [2]. Our case highlights the need for prompt identification and clarification of coexistent neurological symptoms such as decreased muscle strength, difficulty in urinating or eating in patients with COVID-19 infection, and adequate management. Even though spinal tap is not indispensable for GBS diagnosis, CSF analysis will help rule out alternative diagnoses. Notably, the presence of SARS-CoV- 2 in CSF is usually negative, as reported in several studies, but its positivity has been reported in a single case [9]. Treatment of GBS continues to be intravenous human immunoglobulin even if associated with SARS-CoV-2 infection. Considering the importance of immunomodulation as a treatment of COVID-19 disease, one can speculate if immunoglobulin in our patient contributed to the positive outcome. This question would be better addressed in multicenter databases because of the rarity of concurrent GBS and COVID-19 disease.

\section{Conclusions}

Our case is illustrative of an immune-associated neurological condition induced by SARS-CoV-2 infection. Antibodies against SARS-CoV-2 can cross-react with peripheral myelin causing GBS, and prompt treatment and adequate support to both conditions are essential to increase the chance of a good outcome. Therefore, physicians should be alert that in patients with COVID-19, identification of unexplained neurological manifestations is crucial to early detection and management of neurological pathology.

\section{Additional Information \\ Disclosures}

Human subjects: Consent was obtained or waived by all participants in this study. Conflicts of interest: In compliance with the ICMJE uniform disclosure form, all authors declare the following: Payment/services info: All authors have declared that no financial support was received from any organization for the submitted work. Financial relationships: All authors have declared that they have no financial relationships at present or within the previous three years with any organizations that might have an interest in the submitted work. Other relationships: All authors have declared that there are no other relationships or activities that could appear to have influenced the submitted work.

\section{References}

1. Wang L: Guillain-Barre syndrome following viral infections: considerations for future treatment and research. Explor Res Hypothesis Med. 2018, 3:4-5. 10.14218/ERHM.2017.00035

2. Toscano G, Palmerini F, Ravaglia S, et al.: Guillain-Barré syndrome associated with SARS-CoV-2 . N Engl J Med. 2020, 382:2574-6. 10.1056/NEJMc2009191 


\section{Cureus}

3. Zubair AS, McAlpine LS, Gardin T, Farhadian S, Kuruvilla DE, Spudich S: Neuropathogenesis and neurologic manifestations of the coronaviruses in the age of coronavirus disease 2019: a review. JAMA Neurol. 2020, 77:1018-27. 10.1001/jamaneurol.2020.2065

4. Johansson A, Mohamed MS, Moulin TC, Schiöth HB: Neurological manifestations of COVID-19: A comprehensive literature review and discussion of mechanisms. J Neuroimmunol. 2021, 358:577658. 10.1016/j.jneuroim.2021.577658

5. Leven Y, Bösel J: Neurological manifestations of COVID-19 - an approach to categories of pathology . Neurol Res Pract. 2021, 3:39. 10.1186/s42466-021-00138-9

6. Hu B, Guo H, Zhou P, Shi ZL: Characteristics of SARS-CoV-2 and COVID-19. Nat Rev Microbiol. 2021, 19:141-54. 10.1038/s41579-020-00459-7

7. Papri N, Hayat S, Mohammed A, et al.: Guillain-Barré syndrome associated with SARS-CoV-2 infection: a case report with long term follow up. J Neuroimmunol. 2021, 356:577590. 10.1016/j.jneuroim.2021.577590

8. Montalvan V, Lee J, Bueso T, De Toledo J, Rivas K: Neurological manifestations of COVID-19 and other coronavirus infections: a systematic review. Clin Neurol Neurosurg. 2020, 194:105921.

10.1016/j.clineuro.2020.105921

9. Domingues RB, Mendes-Correa MC, de Moura Leite FB, et al.: First case of SARS-COV-2 sequencing in cerebrospinal fluid of a patient with suspected demyelinating disease. J Neurol. 2020, 267:3154-6. 10.1007/s00415-020-09996-w 